"This document is the Accepted Manuscript version of a Published Work that appeared in final form in Organic letters copyright American Chemical Society after peer review and technical editing by the publisher. To access the final edited and published work, see http://pubs.acs.org/doi/pdf/10.1021/acs.orglett.6b01368"

\title{
Regioselective Intermolecular Diamination and Aminooxygenation of Alkenes with Saccharin
}

\author{
Claudio Martínez, ${ }^{\dagger}$ Edwin G. Pérez, ${ }^{\dagger}$ Álvaro Iglesias, ${ }^{\dagger}$ Eduardo C. Escudero-Adán, ${ }^{\dagger}$ and Kilian \\ Muñiz*†
}

${ }^{\dagger}$ Institute of Chemical Research of Catalonia (ICIQ), The Barcelona Institute of Science and Technology, Av. Països Catalans 16, 43007 Tarragona, Spain.

\$Departamento de Química Orgánica, Facultad de Química, Pontificia Universidad Católica de Chile, Vicuña Mackenna 4860, Casilla 306, Santiago, Chile.

${ }^{\star}$ Catalan Institution for Research and Advanced Studies (ICREA), Pg. Lluís Companys 23, 08010 Barcelona, Spain.

Supporting Information Placeholder

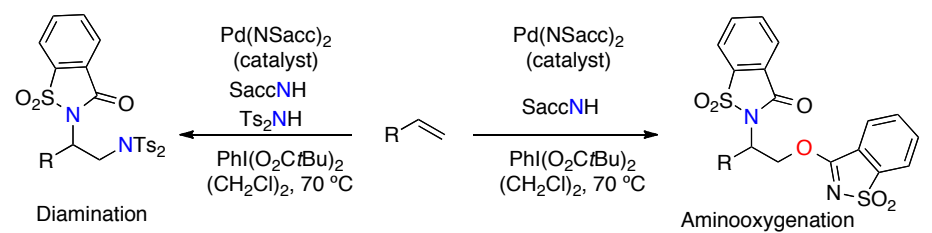

ABSTRACT: Palladium catalysis enables the regioselective difunctionalization of alkenes using saccharin as the nitrogen source in
the initial step of aminopalladation. Depending on the reaction conditions, diamination or aminooxygenation pathways can be ac-
cessed using hypervalent iodine reagents as the terminal oxidants. The aminooxygenation of allylic ethers originates from an un-
precedented ambident behavior of saccharine. The participating palladium catalysts contain a palladium-saccharide unit. Two rep-
resentative complexes of this type could be isolated and characterized.

The oxidative difunctionalization of alkenes represents a powerful tool for the efficient 1,2-introduction of heteroatoms into organic framework and thus for structural diversification from common hydrocarbon groups. ${ }^{1}$ Within such vicinal difunctionalization, palladium catalysis constitutes a particularly effective approach. In this particular area, the development of conditions that are applicable to intermolecular reaction control are of particular challenge. A currently limited number of different protocols have become available including dihalogenation, ${ }^{2}$ dioxygenation, ${ }^{3}$ aminooxygenation, ${ }^{4}$ aminofluorination ${ }^{5}$ and diamination ${ }^{6}$ reactions.

Since vicinal diamines constitute an important class of functional groups that are present in a number of molecular entities of pharmaceutical and medicinal interest, ${ }^{7}$ function as effective ligands to transition metals to provide catalysts, ${ }^{8,9}$ the development of new avenues for their synthesis is of major interest. Within this context, the direct vicinal diamination of alkenes offers a straightforward access, ${ }^{10}$ and we have been interested in devising suitable reaction conditions that enable palladium catalysis to operate under completely intermolecular conditions. ${ }^{6,11}$

Some time ago, we introduced saccharin as a useful nitrogen source in the palladium-catalyzed vicinal diamination of alkenes under intermolecular reaction control. ${ }^{6 a}$ The combination of this particular imine together with iodosobenzene diacetate and bissulfonylimines as a second nitrogen source enabled the realization of the first regio and chemoselective diamination of terminal alkenes. Saccharin owes its attractiveness as a nitrogen source to its commercial availability and low price.

We recently investigated the composition of the active palladium catalyst in related oxidative amination reactions of alkenes with phthalimide. ${ }^{12}$ We could demonstrate that the initial palladium dichloride or diacetate salt is readily transformed into the corresponding bisphthalimidato palladium derivatives at the outset of the reaction.

We were intrigued to study the performance of these common palladium salts in the presence of saccharin $\mathbf{1}$ as well. Indeed, when an acetonitrile solution of palladium diacetate $\mathbf{2}$ is treated with 2 equivalents saccharin $\mathbf{1}$, clean formation of the new bisacetonitrile palladium disaccharide complex $\mathbf{3}$ is observed. This complex is obtained as a stable yellowish solid (Scheme 1). Attempts to crystallize this compound from organic solvents were not successful. Instead, loss of the acetonitrile ligands occurred leading to formation of the trimeric palladium complex 5. For the reaction in dichloromethane, $\mathbf{5}$ is obtained as an yellow to orange solid in quantitative yield. In a similar manner, when palladium dichloride $\mathbf{4}$ is treated with saccharin $\mathbf{1}$ at elevated temperature, quantitative formation of complex $\mathbf{5}$ is observed. Crystals suitable for X-ray crystallographic analysis were grown from a solution in warm toluene. The resulting solid state structure of 5 is depicted in Figure 1 . In contrast to the related phthalimido complex, $\left[\mathrm{Pd}_{3}(\mathrm{NPhth})_{6}\right]{ }^{12}$ complex $\left[\mathrm{Pd}_{3}(\mathrm{NSacc})_{6}\right] \mathbf{5}$ displays $\mathrm{C} 3$ helical chirality. 
Scheme 1. Formation of bissaccharido palladium(II) complexes 3 and $\mathbf{5 .}$<smiles>O=C1N[SH+](=O)c2ccccc21</smiles>

1<smiles>CC#[N+][Pb](N=CC)(n1sc2ccccc2c1=O)n1sc2ccccc2c1=O</smiles>

$3(\mathrm{MeCN})_{2} \mathrm{PdCl}_{2} 4$

6

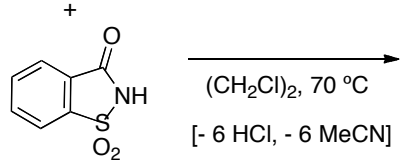

$3(99 \%)$

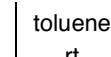

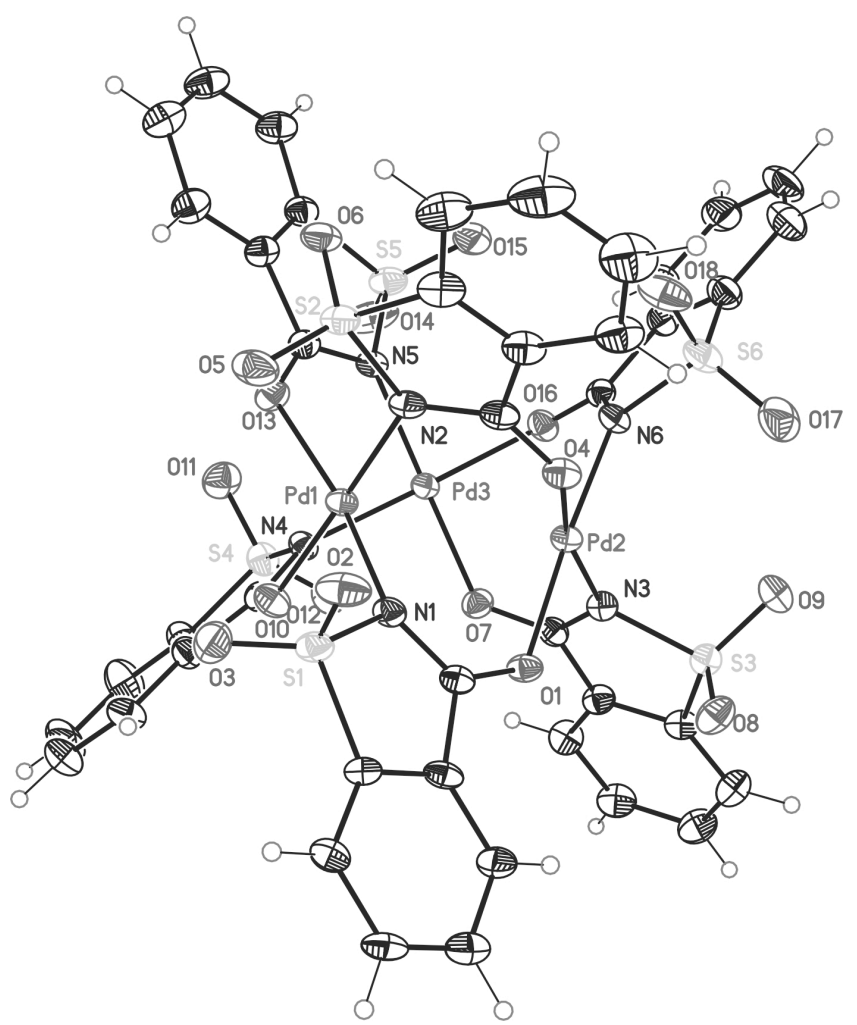

Figure 1. Molecular structure of $\left[\mathrm{Pd}_{3}(\mathrm{NSacc})_{6}\right] 5$ in the solid state (X-ray structure). Selected bond lengths $(\AA)$ and angles $\left({ }^{\circ}\right)$ for one palladium unit: Pd1 N1 1.996(5), Pd1 N2 1.999(6), Pd1 O10 2.007(5), Pd1 O13 2.022(5), N1 Pd1 N2 90.2(2), N1 Pd1 O10 86.6(2), N2 Pd1 O10 174.5(2), N1 Pd1 O13 168.1(2).

The two compounds $\mathbf{3}$ and $\mathbf{5}$ display the expected features. Complex $\mathbf{3}$ is stable in the presence of hypervalent iodine reagents such as $\mathrm{PhI}(\mathrm{OAc})_{2}$ and $\mathrm{PhI}\left(\mathrm{O}_{2} \mathrm{CtBu}\right)_{2}$ as expected for a palladium(II) compound involved in oxidation reactions in the presence of these reagents. Complex $\mathbf{5}$ is stable in isolated form in the solid state and in solution, while it dissociates back to monomeric palladium complexes in the presence of donor ligands. With the isolated bissaccharidato palladium complex 3 containing defined palladium-nitrogen bonds in hand, we investigated its behavior in the catalytic diamination of alkenes and started our exploration for the known transformation of 1-octene 6a. Using catalytic amounts of preformed $\mathbf{3}$, this alkene undergoes the reported diamination reaction to the expected product 7a in $80 \%$ yield (Table 1). This compares well to the $74 \%$ yield obtained for the corresponding diamination with the previously reported $\mathrm{Pd}(\mathrm{NCMe})_{2} \mathrm{Cl}_{2}$ catalyst. ${ }^{6 \mathrm{a}}$ Related alkenes 1 -hexene $\mathbf{6 b}, 1$-decene $\mathbf{6 c}$ and 1 -duodecene $\mathbf{6 d}$ give the corresponding diamination products $\mathbf{7 b - d}$ in $60-73 \%$ yield. 4-Phenyl butene 6e provides diamine $7 \mathbf{e}$ in $55 \%$ yield. Im- 
portantly, allylbenzene 6 f gives a clean diamination product $7 \mathbf{f}$ in $63 \%$ yield, while under the previous conditions the predominant product is alkene isomerization catalyzed by $\mathrm{Pd}(\mathrm{NCMe})_{2} \mathrm{Cl}_{2} .{ }^{13}$ As observed for the related compound $\mathrm{Pd}(\mathrm{NCMe})_{2}(\mathrm{NPhth})_{2}$, ${ }^{12}$ $\mathrm{Pd}(\mathrm{NCMe})_{2}(\mathrm{NSacc})_{2}$ does not promote alkene isomerization under the reaction conditions of diamination. This reaction outcome of chemoselective diamination of allylbenzene $\mathbf{7 f}$ is also obtained when the bissulfonylimide is bismesylimide or mesyltosylimide, which lead to formation of compounds $7 \mathbf{g}$ and $\mathbf{7 h}$, respectively.

Scheme 2. Palladium-catalyzed diamination of terminal alkenes with isolated complex 3.

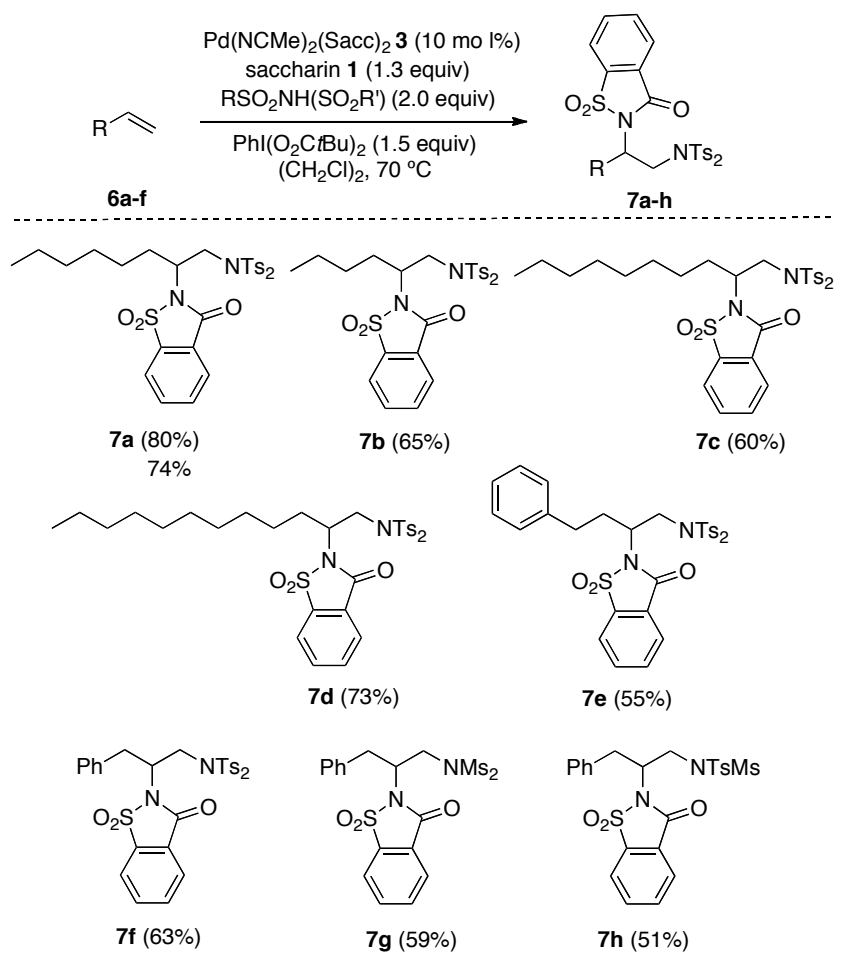

When the diamination reaction was attempted under the same conditions with allyl propylether 8a, no desired diamination product was observed in the crude reaction mixture. This result matches earlier observations, which had led us to develop the corresponding diamination reactions using phthalimide as nitrogen source. ${ }^{6 \mathrm{~b}}$ However, in the present case, a small amount of the unprecedented difunctionalization product could be obtained in less than $10 \%$ yield. This compound turned out to be the vicinal aminooxygenated product 9a from incorporation of two saccharine units (Scheme 3). Since there was no apparent incorporation of the bistosylimide into the oxidation product, subsequent experimentation employed a double amount of saccharin. In this way aminooxygenation product 9a was obtained in $73 \%$ isolated yield. Its structure was unambiguously determined by X-ray analysis.

Scheme 3. Palladium-catalyzed aminooxygenation of allyl ethers and esters 8. 


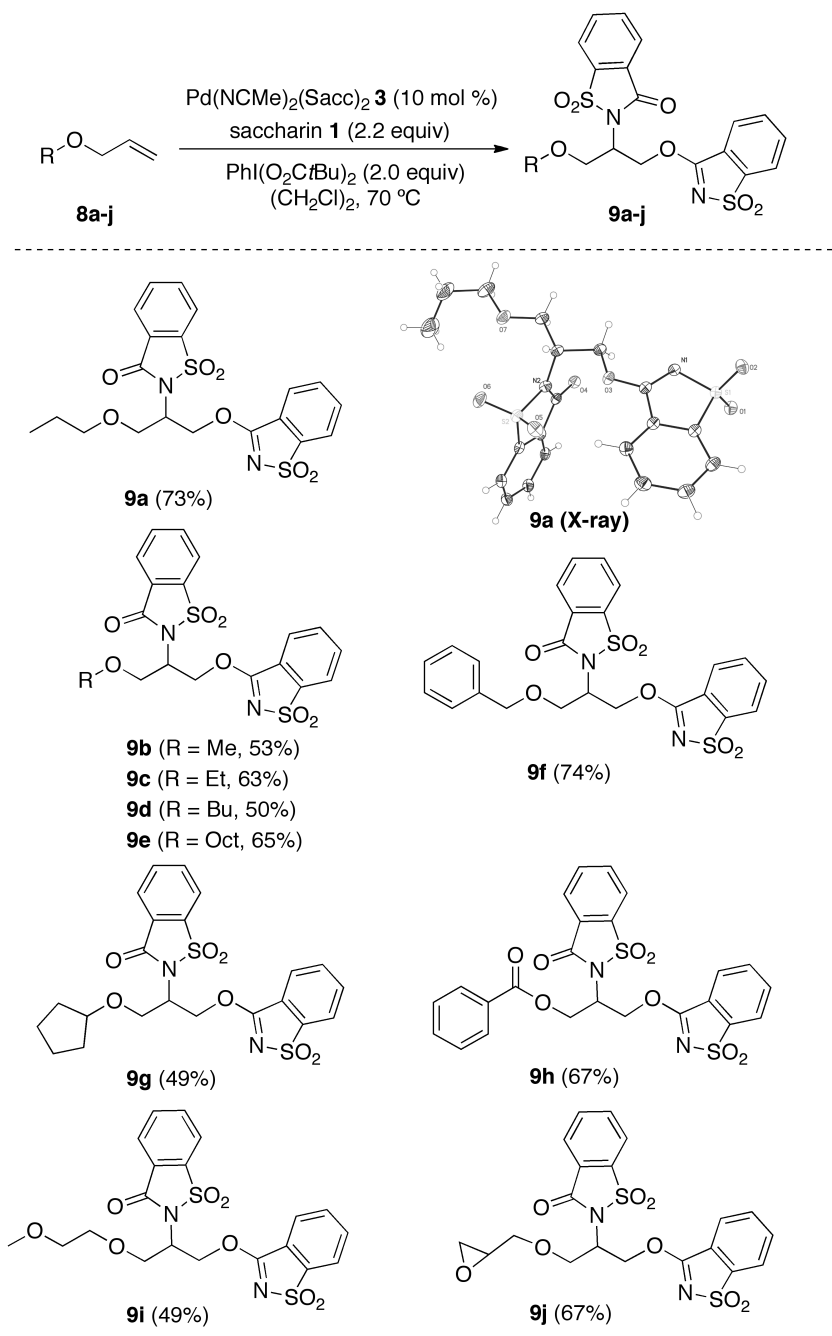

This unprecedented aminooxygenation reaction proofed general under the given reaction conditions. In addition to 9a, related allyl $n$-alkylethers $\mathbf{8 b}$-e give the corresponding difunctionalization products $\mathbf{9 b}$-e in 50-65\% yield. The benzyl derivative $\mathbf{9 f}$ was formed in $74 \%$, and the reaction could be extended to secondary alkyl ethers such as the pentyl derivative $9 \mathrm{~g}$ (49\% yield). The benzoyl ester $9 \mathbf{h}$ was obtained in $67 \%$ yield and higher-functionalized products $9 \mathbf{i}$ and $9 \mathbf{j}$ incorporating a methoxyethylenyl and glycidyl unit were produced in 49 and $67 \%$ yield, respectively. Importantly, under these conditions, terminal alkenes 6 are completely unreactive.

The mechanistic proposal for the present difunctionalization reactions is given in Figure 2. The reaction starts from palladium catalyst 3, which engages in aminometalation with saccharin to arrive regioselectively at the anti-Markovnikov aminopalladated intermediate A. ${ }^{14}$ Metal oxidation to high oxidation state palladium(IV) intermediate $\mathbf{B}^{15}$ is accomplished with the hypervalent iodine reagent. The diamination pathway proceeds through commonly observed nucleophilic attack of bissulfonimide at the $\alpha$-carbon of the $\sigma$-alkylpalladium(IV) leads to diamination products $7 .{ }^{16}$ In the case of nucleophilic addition of saccharin, the nucleophilic displacement takes place via oxygenation to provide aminooxygenation products $\mathbf{9}$. In both cases, the palladium(II) catalyst $\mathbf{3}$ is regenerated. 


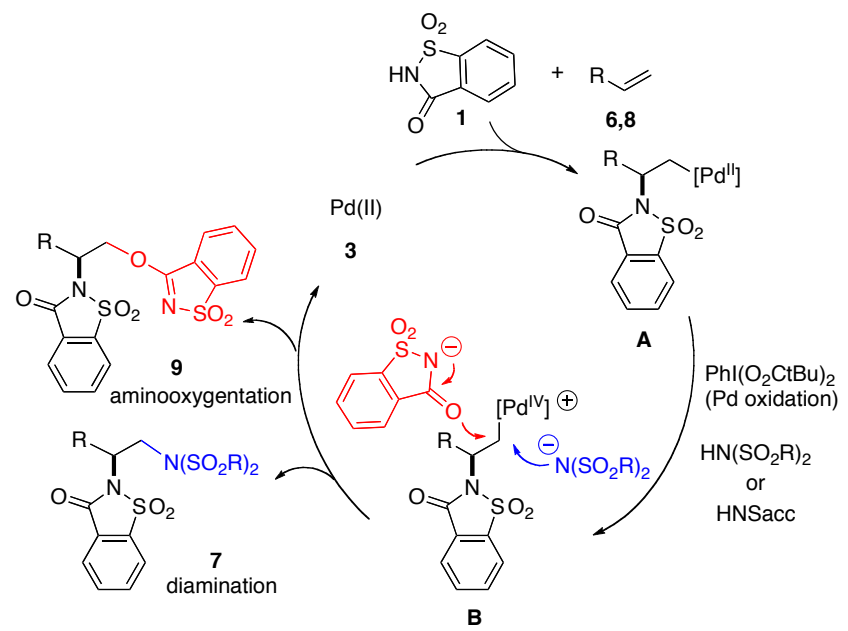

Figure 2. Mechanistic scenario for palladium-catalyzed difunctionalization reactions with saccharin.

Obviously, saccharin displays an ambident behavior in the latter alkene difunctionalization. While in engages in a C-N bond formation within the initial aminopalladation, after oxidation to $\mathbf{B}$, the subsequent reductive elimination involves the tautomeric anion of saccharide resulting in $\mathrm{C}-\mathrm{O}$ bond formation. This outcome is rather unexpected as an earlier study on an oxidation of an isolated palladium saccharinato complex had suggested clean $\mathrm{C}-\mathrm{N}$ bond formation. ${ }^{16 \mathrm{c}}$ Moreover, studies by Mayr had revealed exclusive amination of the diphenylmethyl cation in the reaction with saccharide. ${ }^{17,18}$ Obviously aminooxygenation products 9 represent kinetic products. We explain the notable difference in the present catalysis by the fact that reductive elimination from the intermediary palladium(IV) catalyst state $\mathbf{B}$ is a fast process resulting in kinetic C-O bond formation. More detailed mechanistic studies are ongoing.

In summary, we have synthesized the first bissaccharido palladium complexes and have investigated their behavior in the vicinal difunctionalization of terminal alkenes.

\section{ASSOCIATED CONTENT}

\section{Supporting Information}

Full experimental details and characterization data for new compounds (pdf format) and details on the X-ray analyses of compounds $\mathbf{5}$ and 9a (cif). This material is available free of charge via the Internet at http://pubs.acs.org

\section{AUTHOR INFORMATION}

\section{Corresponding Author}

* Email address: kmuniz@iciq.es.

\section{Author Contributions}

The manuscript was jointly written by all authors. All authors have given approval to the final version of the manuscript.

\section{Notes}

The authors declare no competing financial interest.

\section{ACKNOWLEDGMENT}

Financial support for this project was provided from the Spanish Ministry for Economy and Competitiveness and FEDER (CTQ201456474R grant to K. M., and Severo Ochoa Excellence Accreditation 2014-2018 to ICIQ, SEV-2013-0319) and the Cellex-ICIQ Program (fellowship to C. M.).

\section{REFERENCES}

(1) (a) Jensen, K. H.; Sigman, M. S. Org. Biomol. Chem. 2008, 6, 4083. (b) Minatti, A.; Muñiz, K. Chem. Soc. Rev. 2007, 36, 1142. (c) McDonald, R. I.; Liu, G.; Stahl, S. S.Chem. Rev. 2011, 111, 2981. (d) Martínez, C.; Muñiz, K. in Metal-Catalyzed Cross-Coupling Reactions and More (Eds.: Bräse, S.; de Meijere, A.; Oestreich, M.), Wiley-VCH, Weinheim 2014, Chapter 16, pp. 1259-1314.

(2) (a) El-Qisairi, A. K.; Qaseer, H. A.; Katsigras, G.; Lorenzi, P.; Trivedi, U.; Tracz, S.; Hartman, A.; Miller, J. A.; Henry, P. M. Org. Lett. 2003, 5, 439. (b) Cresswell, A. J.; Eey, S. T.-C., Denmark, S. E. Angew. Chem. Int. Ed. 2015, 54, 15642.

(3) (a) Pathak, T.P.; Sigman, M. S. J. Org. Chem. 2011, 76, 9210. (b) Jensen, K.H.; Pathak, T. P.; Zhang, Y.; Sigman, M. S. J. Am. Chem. Soc. 2009, 131, 17074. (c) Jensen, K. H.; Webb, J. D.; Sigman, M. S. J. Am. Chem. Soc. 2010, 132, 17471. (d) Y. Li, D. Song, V. M. Dong, J. Am. Chem. Soc. 2008, 130, 2962. (e) Kang, Y.-B.; Gade, L. H. J. Am. Chem. Soc. 2011, 133, 3658. 
(4) (a) Liu, G.; Stahl, S. S. J. Am. Chem. Soc. 2006, 128, 7179. (b) Martinez, C.; Wu, Y.; Weinstein, A. B.; Stahl, S. S.; Liu, G.; Muñiz, K. J. Org. Chem. 2013, 78, 6309.

(5) (a) Qiu, S.; Xu, T.; Zhou, J.; Guo, Y.; Liu, G. J. Am. Chem. Soc. 2010, 132, 2856. (b) Chen, P.; Liu, G. Eur. J. Org. Chem. $2015,4295$.

(6) (a) Iglesias, Á.; Pérez, E. G.; Muñiz, K. Angew. Chem. Int. Ed. 2010, 49, 8109. (b) Muñiz, K.; Kirsch, J.; Chávez, P. Adv. Synth. Catal. 2011, 353, 689. (c) Martínez, C.; Muñiz, K. Angew. Chem., Int. Ed. 2012, 51, 7031.

(7) (a) Lucet, D.; Le Gall, T.; Mioskowski, C. Angew. Chem. Int. Ed. 1998, 37, 2580. (b) Kiziran, J.-C. Chem. Rev. 2008, 108, 140. (c) Kotti, S. R. S. S.; Timmons, C.; Li, G. Chem. Biol. Drug Des. 2006, 67, 101.

(8) For chiral catalysts: (a) Noyori, R. Angew. Chem. Int. Ed. 2002, 41, 2008. (b) Noyori, R. Adv. Synth. Catal. 2003, 345, 15. (c) Noyori, R.; Hachiguchi, S. Acc. Chem. Res. 1997, 30, 97. (d) Kuwata, S.; Ikariya, T. Dalton Trans. 2010, 39, 2984. (e) Ikariya, T.; Blacker, A. J. Acc. Chem. Res. 2007, 40, 1300. (f) Ikariya, T.; Gridnev, I. D. Chem. Rec. 2009, 9, 106. (g) Grützmacher, H. Angew. Chem. Int. Ed. 2008, 47, 1814. (h) van der Vlugt, J. I.; Reek, J. N. H. Angew. Chem. Int. Ed. 2009, 48, 8832. (i) Muñiz, K. Angew. Chem. Int. Ed. 2005, 44, 6622. (j) Ikariya, T. Bull. Chem. Soc. Jpn. 2011, 84, 1.

(9) For achiral catalysts: (a) Surry, D. S.; Buchwald, S. L. Chem Sci. 2010, 1, 13. (b) Jiang, Y.; Ma, D. in Copper-Mediated Cross-Coupling Reactions (Evano, G.; Blanchard, N., Eds.), Wiley, New York, 2014, Chapter 1, pp. 3-40.

(10) (a) de Jong, S.; Nosal, D. G.; Wardrop, D. J. Tetrahedron 2012, 68, 4067. (b) Cardona, F.; Goti, A. Nat. Chem. 2009, 1, 269. (c) de Figueiredo, R. M. Angew. Chem. Int. Ed. 2009, 48, 1190. (d) Martínez, C.; Muñiz, K. J. Org. Chem. 2013, 78, 2168. (e) Zhu, Y.; Cornwall, R. G.; Du, H.; Zhao, B.; Shi, Y. Acc. Chem. Res. 2014, 47, 3665. (f) Muñiz, K. New J. Chem. 2005, 29, 1371. (g) Muñiz, K. Chem. Soc. Rev. 2004, 33, 166. (f) Muñiz, K.; Hövelmann, C. H.; Streuff, J.; Campos-Gómez, E. Pure Appl. Chem. 2008, 80, 1089. (g) Muñiz, K.; Nieger, M.; Mansikkamäki, H. Angew. Chem. Int. Ed. 2003, 425, 5958.

(11) For the background reaction based on hypervalent iodine chemistry: (a) Röben, C.; Souto, J. A.; González, Y.; Lishchynskyi, A.; Muñiz, K. Angew. Chem., Int. Ed. 2011, 50, 9478. (b) Souto, J. A.; Martínez, C.; Velilla, I.; Muñiz, K. Angew. Chem., Int. Ed. 2013, 52, 1324. (c) Souto, J. A.; González, Y.; Iglesias, Á.; Zian, D.; Lishchynskyi, A.; Muñiz, K. Chem. Asian J. 2012, 7, 1103. (d) Röben, C.; Souto, J. A.; Escudero-Adán, E. C. Muñiz, K. Org. Lett. 2013, 15, 1008.

(12) Martínez, C.; Muñiz, K. Chem. Eur. J. 2016, 22, 7367.

(13) Tan, E. H. P.; Lloyd-Jones, G. C.; Harvey, J. N.; Lennox, A. J. J.; Mills, B. M. Angew. Chem., Int. Ed. 2011, 50, 9602.

(14) (a) Zeni, G.; Larock, R. C. Chem. Rev. 2004, 104, 2285. (b) Beccali, E. M.; Broggini, G.; Martinelli, M.; Sottocornola, S. Chem. Rev. 2007, 107, 5318. (c) Minatti, A.; Muñiz, K. Chem. Soc. Rev. 2007, 36, 1142. (d) Kotov, V.; Scarborough, C. C.; Stahl, S. S. Inorg. Chem. 2007, 46, 1910. (e) Jensen, K. H.; Sigman, M. S. Org. Biomol. Chem. 2008, 6, 4083. (f) McDonald, R. I.; Liu, G.; Stahl, S. S. Chem. Rev. 2011, 111, 2981.

(15) (a) Canty, A. J. Dalton. Trans. 2009, 47, 10409. (b) Hickman, A. J.; Sanford, M. S. Nature 2012, 484, 177. (c) Muñiz, K. Angew. Chem., Int. Ed. 2009, 48, 9412.

(16) (a) Peng, H.; Yuan, Z.; Wang, H.-y.; Guo, Y.-I.; Liu, G. Chem. Sci. 2013, 4, 3172. (b) Pérez-Temprano, M. H.; Racowski, J. M.; Kampf, J. W.; Sanford, M. S. J. Am. Chem. Soc. 2014, 136, 4097. (c) Iglesias, A.; Alvarez, A.; de Lera, A. R.; Muñiz, K. Angew. Chem., Int. Ed. 2012, 51, 2225. (d) Iglesias, A.; Muñiz, K. Helv. Chim. Acta 2012, 95, 2007. (e) Sibbald, P. A.; Rosewall, C. F.; Swartz, R. D.; Michael, F. E. J. Am. Chem. Soc. 2009, 131, 15945. (f) Muñiz, K.; Hövelmann, C. H.; Streuff, J. J. Am. Chem. Soc. 2008, 130, 763. (g) Pendleton, I. M.; Pérez-Temprano, M. H.; Sanford, M. S.; Zimmermann, P. M. J. Am. Chem. Soc. 2016, 138, 6049.

(17) Breugst, M.; Tokuyasu, T.; Mayr, H. J. Org. Chem. 2010, 75, 5250.

(18) For the observation of related O-alkylation: Yoshimura, A.; Koski, S. R.; Fuchs, J. M.; Saito, A.; Nemykin, V. N.; Zhdankin, V. V. Chem. Eur. J. 2015, 21, 5328.

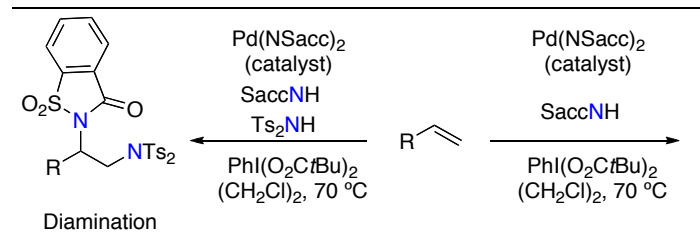

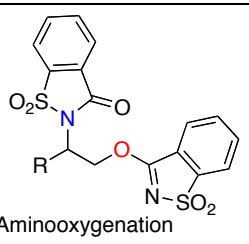

